\title{
FRONTEIRA E CONSTRUÇÃO DO “OUTRO” concepções de alunos sobre povos indígenas
}

\author{
the border and the construction of the "other": conceptions from elementary \\ school students about the indigenous peoples \\ Flaviana Gasparotti Nunes* \\ Solange Rodrigues da Silva **
}

\begin{abstract}
Resumo
Neste texto pretendemos discutir algumas ideias que consideramos relevantes para a Geografia na atualidade e dizem respeito à importância que questões relativas à identidade têm adquirido para a compreensão dos processos e práticas socioespaciais. Nossa reflexão sobre identidade desdobra-se da ideia de fronteira que tomamos como ponto de partida para a discussão. A fronteira, neste caso, é entendida como lugar da alteridade, um território de invenção do outro, onde o indivíduo procura se reconhecer frente à alteridade. Com base nesse percurso teórico, analisamos como tais questões estão presentes e permeiam as concepções de alunos do Ensino Fundamental sobre os povos indígenas de Dourados (MS). A partir da análise de atividades realizadas com alunos do Ensino Fundamental de Dourados (MS), procuramos refletir sobre fronteira, identidade e alteridade. Concluímos que as concepções dos alunos se constroem a partir da distinção entre o "eu" e o "outro", portanto, da marcação das diferenças existentes entre indígenas e não-indígenas estabelecidas por elementos e parâmetros que permeiam sistemas simbólicos de representação, bem como por formas de exclusão social que envolvem relações de poder.
\end{abstract}

Palavras-chave: Identidade; Fronteira; Alteridade; Povos indígenas.

\begin{abstract}
In this text, we try to discuss some ideas that we consider to be relevant to the Geography in this current period and these ideas take into consideration the importance that the matters relative to the identity have acquired for the understanding of the social-spatial processes and practices. Our reflection on identity is unfolded thanks to the idea of borders that we take as a starting point for this discussion. The border here is understood as a place of otherness, a territory of invention for the other, where the individual seeks to recognize themselves within the otherness. Based on this theoretical route, we analyze how such issues are present and permeate the conceptions of elementary school students about the indigenous peoples of Dourados/MS. Based on the analysis of the activities carried out with students in Dourados/MS, we seek to reflect on borders, identity and otherness. We concluded that the students' conceptions are constructed due to the distinction between the "I" and the "other", i.e., the marking of the differences between indigenous and non-indigenous established by elements and parameters that permeate the systems of symbolic representation and also forms of social exclusion involving power relations.
\end{abstract}

Key words: Identity; Border; Otherness; Indigenous peoples.

\section{Resumen}

En este texto pretendemos discutir algunas ideas que consideramos relevantes para la Geografía en la actualidad y que se refieren a la importancia últimamente adquirida por cuestiones relativas a la identidad para la comprensión de los procesos y prácticas socioespaciales. Nuestra reflexión sobre la identidad se desarrolla a partir de la idea de frontera que tomamos como punto de partida para la discusión. Se entiende la frontera, en este caso, como el lugar de la alteridad, un territorio de invención del otro, donde el individuo busca reconocerse frente a la alteridad. Con base en ese recorrido teórico, analizamos como tales cuestiones están presentes y permean las concepciones de alumnos de la Enseñanza Fundamental sobre los pueblos indígenas de Dourados (MS). A partir del análisis de actividades realizadas con alumnos de Dourados (MS), buscamos reflexionar sobre frontera, identidad y alteridad. Concluimos que las concepciones de los alumnos se construyen a partir de la distinción entre el "yo" y el "otro", es decir, a partir de la marcación de las diferencias existentes entre indígenas y no indígenas establecidas por elementos y parámetros que permean sistemas simbólicos de representación, así como por formas de exclusión social que involucran relaciones de poder.

Palabras-clave: Identidad; Frontera; Alteridad; Pueblos indígenas.

(*) Prof ${ }^{\mathrm{a}} \mathrm{Dr}^{\mathrm{a}}$ do Programa de Pós-Graduação em Geografia da Universidade Federal da Grande Dourados - Rod. DouradosItahum, Km 12, CEP: 79804-970, Dourados (MS), Brasil. Tel: (+55 67) 34102270 - flaviananunes@ufgd.edu.br

(**) Mestre em Geografia pela Universidade Federal da Grande Dourados - Rua Geronimo M. de Mattos 550, casa 32, CEP: 79823-855, Dourados (MS), Brasil. Tel: (+55 67) 34102270- so_ufms@hotmail.com 
NUNES, F. G.; SILVA, S. R.

\section{INTRODUÇÃO}

Nossa pretensão neste texto é discutir algumas ideias que consideramos relevantes para a Geografia na atualidade e dizem respeito à importância que questões sobre a identidade têm adquirido para a compreensão dos processos e práticas socioespaciais.

Em nosso entendimento, as práticas socioespaciais construídas cotidianamente são permeadas por elementos que constituem identidades estabelecendo distinções entre os sujeitos e que definem o "lugar" dos mesmos, uns em relação aos outros, ao mesmo tempo em que produzem espacialidades as mais diversas possíveis.

Pretendemos que a reflexão aqui desenvolvida possa fomentar e contribuir para o debate sobre a construção de uma sociedade em que as diferenças permitam o diálogo solidário entre os sujeitos na perspectiva que autores como Tubino $(2002$; 2004) têm denominado interculturalidade. Acreditamos que os elementos conceituais levantados, bem como o exercício analítico desenvolvido a partir dos mesmos podem auxiliar a Geografia a melhor se posicionar e compreender as práticas socioespaciais cotidianamente construídas em nossa sociedade e que envolvem processos constantes de marcação de diferenças e constituição de identidades.

Nos últimos anos, um conjunto significativo de reflexões têm sido desenvolvidas em torno da questão da identidade. Podemos destacar os estudos de Hall (2000; 2006), Bauman (2005), Woodward (2006) e no campo da Geografia, em específico, as contribuições de Haesbaert (1999, 2004, entre outras).

Nossa reflexão sobre identidade pauta-se nas reflexões desses autores, mas desdobra-se da ideia de fronteira que tomamos como ponto de partida para a discussão. A fronteira, neste caso, é entendida como lugar da alteridade, um território de invenção do outro, onde o indivíduo procura se reconhecer frente à alteridade, conforme discutiremos no decorrer do texto.

Com base nesse percurso teórico, analisamos como tais questões estão presentes e permeiam as concepções de alunos do Ensino Fundamental sobre os povos indígenas de Dourados (MS).

O estado de Mato Grosso do Sul possui segunda maior população indígena do país sendo que o município de Dourados concentra a maior população indígena desse estado. A expressiva presença de aldeias indígenas no município de Dourados e a problemática intrínseca à relação desses povos com demais moradores da cidade propicia um interessante contexto para a reflexão aqui proposta, pois entendemos que ali se instaura uma situação de fronteira.

Sendo assim, a partir da análise de atividades realizadas com alunos do $6^{\circ}, 7^{\circ}$ e $8^{\circ}$ ano do Ensino Fundamental da Escola Municipal Luiz Antonio Álvares Gonçalves de Dourados (MS) procuramos refletir sobre as relações entre fronteira, identidade e alteridade.

Nessas atividades, por meio da elaboração de desenhos e textos, os alunos expuseram suas visões sobre a maneira como vivem os povos indígenas do município em que residem, bem como a forma com a qual eles se relacionam com os mesmos. Essa atividade foi proposta com o objetivo de identificar a maneira como os alunos enxergavam (ou não) os povos indígenas do município de Dourados, uma vez, que apesar da significativa presença desses na cidade e a existência de alunos indígenas matriculados na escola, percebia-se em algumas falas e comportamentos em sala de aula, certa resistência e até mesmo negação da existência desses povos no cotidiano dos alunos. É importante destacar que a segunda autora deste texto atuou como docente de Geografia no ano de 2011 nas turmas em que a atividade foi realizada, daí a possibilidade de identificação dessas situações em sala de aula.

No texto que segue procuramos problematizar e analisar as concepções desses alunos como forma de demonstrar a relevância desta reflexão não só para os processos educativos, como também para a análise geográfica em sua amplitude. 


\section{IDENTIDADE E ALTERIDADE: quando a fronteira revela o eu e o "outro"}

Inicialmente, é necessário esclarecer que trabalharemos neste texto com a ideia de fronteira para além de sua conotação enquanto limite político-administrativo, pois:

Antes de serem marcos físicos ou naturais, as fronteiras são, sobretudo, o produto da capacidade imaginária de refigurar a realidade, a partir de um mundo paralelo de sinais que guiam o olhar e a apreciação, por intermédio dos quais os homens e as mulheres percebem e qualificam a si mesmos, o corpo social, o espaço e o próprio tempo. (...) (HANCIAU, 2005, p. 135-136)

Desta forma, a ideia de fronteira sempre implicará na construção de identidades e alteridades conforme exposto por Pesavento (2001, p. 7-8) apud Hanciau (2005):

A fronteira constitui-se em encerramento de um espaço, limitação de algo, fixação de um conteúdo e de sentidos específicos, conceito que avança para os domínios da construção simbólica de pertencimento denominada identidade e que corresponde a um marco de referência imaginária, definido pela diferença e alteridade na relação com o outro.

Na mesma direção, tomamos também as ideias de Martins (1997) para o qual a fronteira deve ser concebida como o lugar da alteridade, pois nela há o embate de temporalidades diversas. Em sua interpretação:

[...] a fronteira é essencialmente o lugar da alteridade. É isso o que faz dela uma realidade singular. A primeira vista é o lugar do encontro dos que por diferentes razões são diferentes entre si, como os índios de um lado e os civilizados de outro; como os grandes proprietários de terra, de um lado, e os camponeses pobres, de outro. Mas o conflito faz com que a fronteira seja essencialmente, a um só tempo, um lugar de descoberta do outro e de desencontro. Não só o desencontro e o conflito decorrentes das diferentes concepções de vida e visões de mundo de cada um desses grupos humanos. O desencontro na fronteira é o desencontro de temporalidades históricas, pois cada um desses grupos está situado diversamente no tempo da História. (MARTINS, 1997, p. 150-151)

Nesse sentido, acreditamos que a fronteira configura-se no que Bhabha (2008) chama de "entre-lugar", ou seja, lugares de criação do novo, nos quais os sujeitos, através de suas vivências e do contato "eu"/outro"ou "nós"/eles" estão em constante construção e reconstrução identitária.

A fronteira, nestes termos, configura-se como um território de invenção do outro, onde o indivíduo procura se reconhecer frente à alteridade. É um "entre-lugar", uma zona de transição entre os diferentes que estão a negociar uma identidade.

Para autores como Guerra (1993, p. 63), identidade:

É um conceito que pretende integrar a percepção e a ação sobre o mundo articulando, não apenas um sistema de representações e imaginários sociais, mas também uma rede de pertenças a categorias sociais específicas. (GUERRA, 1993, p. 63)

Com base nas ideias desse autor, podemos dizer que a identidade estabelece relação com o "modo de vida" elaborado pelas relações humanas em cada lugar em que as mesmas se territorializam, permitindo, assim, construir ao longo do tempo histórico e por meio das rotinas cotidianas, o sentido de pertencimento de cada indivíduo com seu grupo e meio.

Neste sentido, pensamos a identidade como um significado cultural e socialmente atribuído, na medida em que as identidades são fabricadas por meio da marcação da diferença, que pode se dar tanto através de sistemas simbólicos de representação ou por formas de exclusão social.

De acordo com Silva (2009, p. 74-75), a identidade deve ser pensada em relação à diferença, na medida em que ambas possuem uma estreita dependência enquanto processos de produção so- 
NUNES, F. G.; SILVA, S. R.

cial permeados por relações de poder. Assim, as afirmações sobre diferença só fazem sentido se compreendidas em sua relação com as afirmações sobre a identidade.

Para o referido autor:

Ver a identidade e a diferença como uma questão de produção significa tratar as relações entre as diferentes culturas não como uma questão de consenso, de diálogo, ou comunicação, mas como uma questão que envolve, fundamentalmente, relações de poder. (SILVA, 2009, p.96)

Para Woodward (2009, p. 39-40): “(...) A identidade, pois, não é o oposto da diferença: a identidade depende da diferença. Nas relações sociais, essas formas de diferença - a simbólica e a social - são estabelecidas, ao menos em parte, por meio de sistemas classificatórios. (...)"

Ao analisar a diferença, a autora $(2009$, p. 49) sugere que as identidades são formadas relativamente a outras identidades. Segundo ela: “(...) Essa construção aparece, mais comumente, sob a forma de oposições binárias. (...)”

Contudo, Woodward (2009, p. 50) destaca que os autores que criticam a oposição binária, argumentam que um dos termos em oposição é sempre mais valorizado ou mais forte que o outro.

É o caso de Silva (2009, p. 83) o qual utilizando da análise do filósofo francês Jacques Derrida, salienta que:

[...] em uma oposição binária, um dos termos é sempre privilegiado, recebendo um valor positivo enquanto o outro recebe um valor negativo. "Nós" e "eles", por exemplo, constitui uma típica oposição binária: não é preciso dizer qual o termo é, aqui, privilegiado. As relações de identidade e diferença ordenam-se, todas, em torno de oposições binárias: masculino/feminino/branco/negro/ heterosexual/ homosexual.[...]

Assim, para Silva (2009, p. 81):

[...] A afirmação da identidade e a enunciação da diferença traduzem o desejo dos diferentes grupos sociais, assimetricamente situados, de garantir o acesso privilegiado aos bens sociais. A identidade e a diferença estão, pois, em estreita conexão com relações de poder. O poder de definir a identidade e de marcar a diferença não pode ser separado das relações mais amplas de poder. [...]

O autor destaca, ainda, que a afirmação da identidade e da diferença implicam, sempre, as operações de incluir e excluir:

[...] A identidade e a diferença se traduzem, assim, em declarações sobre quem pertence e quem não pertence, sobre quem está incluído e quem está excluído. Afirmar a identidade significa demarcar fronteiras, significa fazer distinções entre o que fica dentro e o que fica fora. A identidade está sempre ligada a uma forte separação entre "nós" e "eles". Essa demarcação de fronteiras, essa separação e distinção supõem e, ao mesmo tempo, afirmam e reafirmam relações de poder. [...]

Dividir o mundo social entre "nós" e "eles" significa classificar [...] Dividir e classificar significa, neste caso, também hierarquizar. Deter o privilégio de classificar significa também deter o privilégio de atribuir diferentes valores aos grupos assim classificados. (SILVA 2009, p.82)

No entanto, Woodward também pondera que apesar da diferença ser construída negativamente, por meio da exclusão, ou da marginalização daquelas pessoas que são constituídas como os "outros", ela pode ser celebrada como fonte da diversidade, heterogeneidade e hibridismo. Em suas palavras:

[...] A diferença pode ser construída negativamente - por meio da exclusão ou da marginalização daquelas pessoas que são definidas como "outros", ou forasteiros. Por outro lado, ela pode ser celebrada como fonte de diversidade, heterogeneidade e hibridismo, sendo vista como fonte enriquecedora [...] (WOODWARD, 2009, p. 50) 
A autora procura destacar o caráter de positividade que a diferença pode conter como forma de afirmar que não devemos encará-la apenas do ponto de vista de sua negatividade que propicia a exclusão e marginalização. Esta é uma forma de não absolutizar a diferença como um elemento e sinônimo de negatividade quando tomada para a análise da identidade.

A partir das ideias até aqui expostas pode-se perceber que a discussão sobre a questão da identidade é bastante ampla e demanda a reflexão sobre uma série de elementos que apenas pontuamos brevemente, mas que entendemos serem suficientes para esclarecermos a partir de quais referenciais analisaremos situações vivenciadas em Dourados (MS) quanto às relações entre populações indígenas e não-indígenas, numa constante situação de fronteira. Apesar do município de Dourados localizar-se na faixa de fronteira (zona fronteiriça que pertence ao bem público da União definida pelo decreto-lei no 852 de 15 de novembro de 1938, em seu artigo $2^{\circ}$, inciso V, como a faixa de 150 quilômetros contíguos aos limites do Brasil com Estados estrangeiros que permanece na Constituição Federal de 1988, artigo 20, parágrafo $2^{\circ}$ ) não é no sentido de fronteira internacional que estamos entendendo-o, conforme ficará claro no desenvolvimento do próximo tópico deste texto.

\section{OS POVOS INDÍGENAS DE DOURADOS (MS): como o “outro” se constrói nas concepções dos alunos do ensino fundamental}

Além dos referenciais teóricos já apresentados, partimos do pressuposto de que há um significativo desconhecimento de grande parte das pessoas a respeito dos povos indígenas do Brasil, o que acaba por intensificar certo preconceito (majoritariamente advindo desse desconhecimento) sobre esses povos.

Vivenciamos essa situação de desconhecimento e, consequentemente, de preconceito, cotidianamente em Dourados (MS) nos mais diversos ambientes, inclusive nas escolas de educação básica.

No intuito de identificar de forma mais objetiva as concepções dos alunos do Ensino Fundamental que pudessem expressar o que de fato pensam em relação aos povos indígenas de Dourados, foram realizadas algumas atividades com 3 turmas da Escola Municipal Luiz Antonio Álvares Gonçalves, localizada na porção sudoeste da cidade, a qual atende um público de baixo poder aquisitivo, inclusive, alguns alunos moradores das aldeias indígenas existentes no município. As atividades realizadas incluíram a produção de textos e desenhos e foram propostas sem qualquer discussão anterior mais aprofundada e problematizadora sobre o assunto, uma vez que o objetivo era identificar a concepção até então trazida pelos alunos sobre o tema proposto. Com base nos elementos apresentados no material produzido é que, posteriormente, foi realizado um trabalho mais cuidadoso com cada uma das turmas.

Mesmo cientes de que não podemos generalizar as concepções desses alunos em relação à população da cidade como um todo, acreditamos que essas crianças acabam por refletir o pensar de grande parte sociedade em que vivemos.

Selecionamos alguns desses desenhos e fragmentos de textos produzidos pelos alunos para desenvolvermos as análises a seguir no intuito de discutirmos como se constroem as relações de identidade e alteridade numa situação de fronteira.

Uma das principais concepções presentes nos desenhos produzidos pelos alunos relaciona-se a uma visão bastante romantizada e generalizada sobre os povos indígenas existentes em Dourados.

As figuras 1 e 2 mostram com clareza essa visão: os índios aparecem sempre vestidos com trajes e adornos "típicos" (como o cocar e a tanga); sua moradia é a oca e suas atividades restringem-se a plantar e fazer fogueiras. 


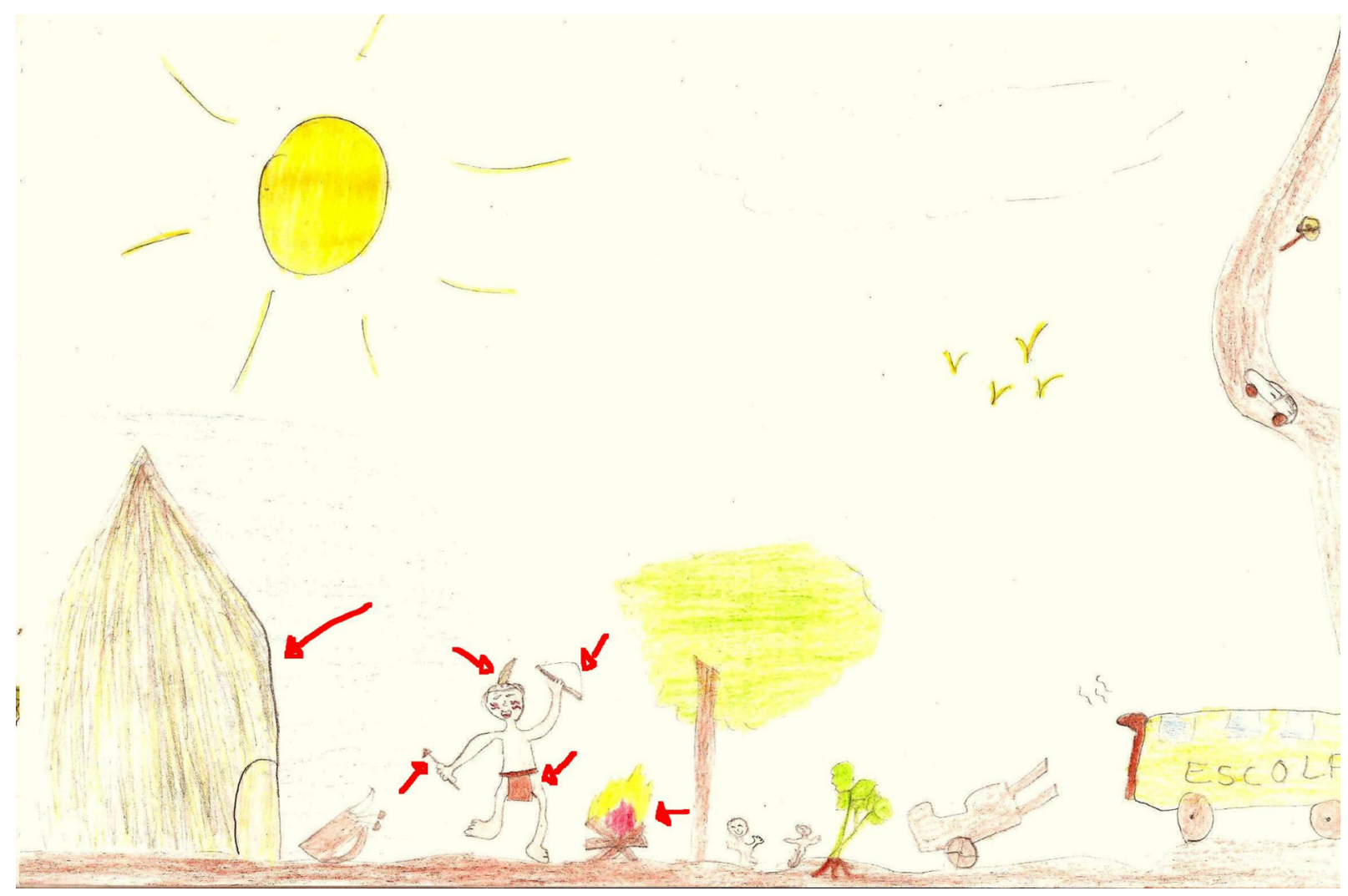

Figura 1 - Representação de aluno do Ensino Fundamental sobre os povos indígenas de Dourados (MS) Fonte: Arquivo pessoal das autoras

A partir destas representações, percebemos que apesar da proximidade física das aldeias com o perímetro urbano do município e o fato dos povos indígenas a todo o momento circularem pelas ruas da cidade, e principalmente, da presença de crianças indígenas na escola, essas pessoas acabam passando despercebidas aos olhos de alguns moradores da cidade.

Há um grande desconhecimento sobre o atual modo de vida dos povos indígenas do município: ao contrário do que comparece na maioria dos desenhos e textos, os indígenas não mais moram em ocas (as habitações das aldeias são, em grande parte, de alvenaria, outras assemelham-se a barracos de madeira) e não andam seminus, pois vestem-se com roupas iguais aos da população não indígena.

Curiosamente, em ambos os desenhos aparece a escola, instituição que não faz parte do "modo de ser tradicional" dos povos indígenas, mas que os alunos possuem conhecimento de sua existência nas aldeias indígenas de Dourados.

Chama atenção também no desenho da figura 2 o fato de que a aluna que o elaborou representou a si própria - ela identifica o "eu" e diz "oi" ao indígena - diferenciando-se desse pela vestimenta. Aqui já aparece claramente a ideia de um "eu/nós" contraposta à concepção de um "outro/eles", conforme discutimos anteriormente.

Nos textos produzidos, tais elementos (desconhecimento sobre o atual modo de vida das populações indígenas de Dourados que produz uma estereotipação dos mesmos e identificação do indígena como o "outro") também se expressaram de forma clara, conforme podemos observar nos trechos a seguir (em todos os trechos transcritos a grafia foi mantida tal como elaborada pelos alunos):

Os indígenas de Dourados vivem em matas limpas, as margens das rodovias. Moram em ocas feitas de folhas de coqueiro. A educação é própria dos indígenas, colocam eles em cadeiras e falam o que é certo e errado. Tomam banhos nos rios e as mulheres amamentam as macaquinhas. (ALUNO DA ESCOLA MUNICIPAL LUIZ ANTÔNIO ÁLVARES GONÇALVES) 
Os índios de Dourados moram em cabanas, vivem da pesca, caça e coleta frutos. As mulheres indígenas lavam roupas e tomam banho no rio. Eles não se vestem como nós. Eu sou diferente deles, porque eles não usam roupas, usam folhas de bananeiras para se vestir, como saias e aquelas coisinhas que colocam na cabeça e que tem cada folhinha de uma cor. E tem também aquela dança maluca deles. Eles não sabem dançar forró e nem rebolar. Eles só sabem dançar a dança que nós também não sabemos. (ALUNO DA ESCOLA MUNICIPAL LUIZ ANTÔNIO ÁLVARES GONÇALVES) (Grifos nossos)

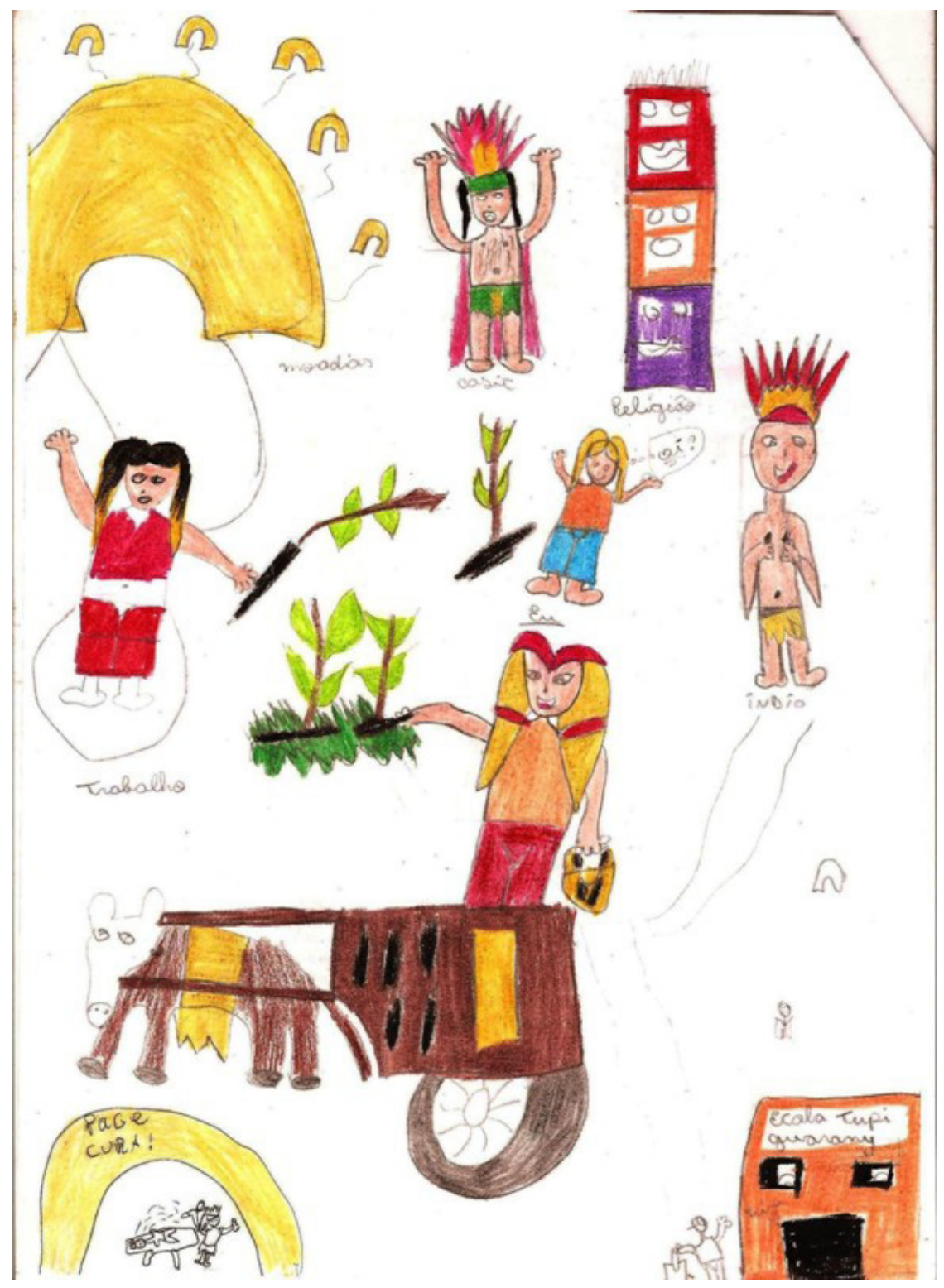

Figura 2 - Representação de aluno do Ensino Fundamental sobre os povos indígenas de Dourados (MS) Fonte: Arquivo pessoal das autoras

Em alguns casos, o estereótipo construído revela concepções preconceituosas e intolerantes. Para Barros (2011) o discurso intolerante é, sobretudo, um discurso de sanção aos sujeitos considerados como maus cumpridores de certos contratos sociais (de branqueamento da sociedade, de pureza linguística, etc.) e que, portanto, devem ser reconhecidos como pretos ignorantes, usuários de língua incorreta, índios bárbaros, judeus exploradores, árabes fanáticos, e punidos (com a perda de direitos, de emprego, com a morte). Concebida a narrativa dessa forma, a intolerância dos dis- 
NUNES, F. G.; SILVA, S. R.

cursos encontra sua justificativa. Nos trechos a seguir podemos identificar elementos nesse sentido (os grifos são nossos):

Os indígenas habitavam a muito tempo o Mato Grosso do Sul. Antes eles eram respeitados agora não. Eu acho que os indígenas não têm nada pra fazer, ficam só pedindo as coisas. Eu queria que eles fossem trabalhar e não mandar os índios de 4 a 5 anos pedir de casa em casa. Eu acho isso muito vergonhoso. (ALUNO DA ESCOLA MUNICIPAL LUIZ ANTÔNIO ÁLVARES GONÇALVES)

Eu tenho medo dos índios porque passa na televisão cada coisa absurda que eles fazem, como por exemplo, os homicídios entre eles. Também acho que os índios podiam se valorizar um pouquinho mais, pois eles andam sujos, com os cabelos embaraçados, e ganham muito dinheiro por cada filho que tem. Os índios têm muito dinheiro, andam de carros, motos, e só andam com aquelas roupas molambentas porque querem. Os índios não precisam pedir esmolas para as pessoas, porque eles ganham muito dinheiro. (ALUNO DA ESCOLA MUNICIPAL LUIZ ANTÔNIO ÁLVARES GONÇALVES)

Para mim os indígenas não têm nada pra fazer. Eles ficam pedindo as coisas, porque querem. E ainda vivem falando no celular. Eu acho que eles deviam trabalhar e não ficar pedindo nas ruas. Eu acho que os índios não trabalham porque não querem, porque oportunidade é o que não falta. (ALUNO DA ESCOLA MUNICIPAL LUIZ ANTÔNIO ÁLVARES GONÇALVES)

É interessante analisarmos alguns elementos contidos nos textos dos alunos. No primeiro trecho, o aluno afirma que "antes eles eram respeitados, agora não"; ao mesmo tempo diz que gostaria que "eles fossem trabalhar e não mandar os índios de 4 e 5 anos pedir de casa em casa". Aqui temos uma concepção que mostra a ideia de um passado harmônico (antes os índios eram respeitados) e um presente em que esse mesmo índio (congelado no passado) está "atrasado" em relação ao presente. As causas, ou o contexto que levaram as crianças indígenas "pedirem de casa em casa", no entanto, não são acionadas, sendo a "culpa" desta situação dos próprios índios, que para se adequarem ao presente devem trabalhar ("eu queria que eles fossem trabalhar").

No segundo trecho, o aluno ressalta elementos da aparência dos indígenas (andam sujos, com cabelos embaraçados, roupas molambentas) bem diferentes da visão expressa nos desenhos das figuras 1 e 2. No entanto, o aluno não questiona as razões para os indígenas assim se apresentarem, ao contrário, afirma que devido ao fato de terem dinheiro (provavelmente esteja referindo-se aos auxílios recebidos pelos indígenas por parte do Estado, como o Bolsa Família, por exemplo) andam assim "porque querem".

No terceiro trecho comparece um elemento fundamental e que em nosso entendimento traz uma possibilidade de problematização mais verticalizada sobre a questão da identidade: o fato de que os índios "vivem falando ao celular". Por que os índios não podem falar ao celular?

Afirma-se aqui, de forma clara, a visão estereotipada do índio, como selvagem (enquanto sinônimo de atraso), parado no tempo, com uma identidade fixa, imutável e circunscrita a determinados elementos. Como o índio é um "outro", conformado por elementos de um passado sinônimo de atraso, não faz sentido, para o aluno (assim como para muitas outras pessoas), que utilize um objeto técnico (o celular) tão próprio de "nós", representantes do presente, do progresso, do avanço. Desta forma, o telefone celular não faz parte dos elementos identificadores do que é o índio - o "outro" - ao contrário, o mesmo elemento identifica quem somos "nós", os não-índios.

A questão da diferença como base para a construção da relação "eu/outro" comparece de forma bastante direta no texto de outro aluno transcrito a seguir:

Os índios não são como nós, eles vivem de maneiras diferentes, moram em aldeias, tomam água de poços, não possuem água encanada. Os índios têm vida muito sofrida. Eu vi na televisão que a maioria 
dos índios invade fazendas, mas também ganham casas da prefeitura. Os índios são muito violentos, nas aldeias acontecem muitas mortes. Os índios não têm moradia fixa, uns tem outros não. Os índios são estranhos, vive de maneira esquisita, diferente, eles são fedidos, são de cores diferentes, se vestem de maneira diferente, as roupas e os sapatos são encardidos. Eles são diferentes dos brasileiros, os brasileiros são mais culturais. (ALUNO DA ESCOLA MUNICIPAL LUIZ ANTÔNIO ÁLVARES GONÇALVES)

O uso dos adjetivos estranho, esquisito, fedido, encardido e diferente traz sempre uma conotação negativa e inferiorizante em relação aos indígenas que auxilia na construção de um "outro" contraposto a um "eu". É interessante observar que a palavra "diferente" foi utilizada várias vezes no texto do aluno como uma necessidade de enfatizar que "eles" não são como "nós". Aúltima frase do texto é bastante significativa neste sentido: a oposição entre índios e brasileiros e a afirmação de que os últimos são "mais culturais", provavelmente entendendo cultura numa linha evolutiva que caminha do atraso em direção ao progresso, da barbárie para a civilização.

Estas visões contribuem, em muitos casos, para a negação da identidade indígena e para o silenciamento de muitos deles. Tal situação/condição aparece no texto produzido por uma indígena, aluna de uma das turmas em que a atividade foi realizada:

Eu não tenho diferenças com os indígenas porque sou uma índia. Nasci e cresci em uma aldeia. Morei lá e depois vim para a cidade. Os indígenas têm costumes e jeitos diferentes dos brancos. Eu só tenho diferenças com os brancos. A maioria dos índios jovens não vem para a cidade porque sofrem preconceito. Quando vem morar na cidade, tem que procurar trabalho, moradia, etc. Muitos preferem dizer que não são índios, por vergonha... Outros têm orgulho disso. Os brancos têm suas diferenças com os indígenas e os indígenas também têm suas diferenças com os brancos. (ALUNA DA ESCOLA MUNICIPAL LUIZ ANTÔNIO ÁLVARES GONÇALVES)

Percebemos no texto da aluna, situações de conflitos que se estabelecem nas relações de encontros e desencontros entre indígenas que migram das aldeias para a cidade e dos não-índios que ali residem. Em relação a essa aluna indígena há uma situação interessante a ser relatada e que reafirma a negação da identidade por parte dos indígenas nesse contexto opressivo em que estão inseridos. No momento da elaboração dos desenhos, a referida aluna justificou o seu desenho, dizendo que apesar de os povos indígenas de Dourados não morarem em ocas, nem andarem de tangas e com penas na cabeça, iria desenhar uma aldeia tal como ela tinha visto em uma reportagem na televisão, porque assim, seu desenho não ficaria diferente em relação ao desenho dos seus colegas de classe.

Essas relações de encontros e desencontros estiveram presentes em grande parte dos desenhos elaborados pelos alunos, nos quais, ao mesmo tempo em que colocavam as relações de encontros com os indígenas, seja comprando mandioca, na escola, no supermercado, ou nas ruas da cidade, utilizaram a régua para delimitar a separação entre o que demarcaram como o meu lugar (nesse caso, a cidade de Dourados) e o lugar dos indígenas (as aldeias). Os desenhos das figuras 3 e 4 expressam essas situações.

Os desenhos das Figuras 3 e 4 demonstram que há, por parte dos alunos, uma necessidade de divisão, entre o "meu mundo" e o "mundo do outro", num sistema de distinções visíveis e invisíveis.

Essa visão comparece, também, em parte dos textos elaborados pelos alunos, que, apesar de conviverem com colegas indígenas na escola, muitas vezes na mesma sala de aula, afirmam não terem qualquer contato com os povos indígenas do seu município, conforme os trechos a seguir:

Eu não conheço, não tenho nenhum contato e por isso não me relaciono com os povos indígenas, mas vou fazer uma história como se tivesse. Os "índios" trabalham como nós, mas tem alguns que não trabalham só pensam em beber pinga e cerveja. Um dia desses eu vi um índio debaixo de uma árvore bêbado. Para provar que são homens eles tem que colocar a mão em abelhas e ficar uns 20 dias. Eu vi na TV. (ALUNO DA ESCOLA MUNICIPAL LUIZ ANTÔNIO ÁLVARES GONÇALVES) 
Eu acredito que os indígenas vivam como pessoas normais. Hoje em dia já não mais como antigamente. Bom eu não sei muito, pois eu não convivo e nem tenho nenhum tipo de contato com eles. Os indígenas devem passar por dificuldades lá na aldeia. Mas eles devem ser felizes, porque é sua maneira de vida. Suas culturas são muito diferentes da nossa, mas eu aprecio pois sou bisneta de índio. (ALUNA DA ESCOLA MUNICIPAL LUIZ ANTÔNIO ÁLVARES GONÇALVES)

Eu não tenho nenhuma relação com os indígenas. Eles moram em outra localidade, e eu sou diferente deles. Eu tenho muitas roupas e eles não. Eu tenho cabelo de um jeito e eles de outro jeito. Eu tenho um nariz diferente deles, uma casa diferente da deles. Eu tenho energia e eles não. (ALUNO DA ESCOLA MUNICIPAL LUIZ ANTÔNIO ÁLVARES GONÇALVES)

Eu não me relaciono com os povos indígenas, mas, imagino que eles vivam assim: para sobreviver eles plantam, caçam, eles trazem alimentos da floresta. Tomam banhos em rios. (ALUNO DA ESCOLA MUNICIPAL LUIZ ANTÔNIO ÁLVARES GONÇALVES)

Os índios de Dourados têm uma moradia simples, eles moram em ocas, e trabalham na roça. A religião deles é qualquer uma diferente da nossa. Eles também têm seus estudos, diferentes dos nossos, mas estudam. Eles usam roupas, não são como as nossas, mas usam um chinelo sujo e roupas rasgadas e sujas. Eu não tenho relação com eles e também não imagino como seria se eu tivesse. Eu não quero ter relação com eles e também não sei o porque. Eu não sinto nada por eles, eu só sinto dó, mas eu não quero ter relação com eles, eu não quero ser amiga deles nem um pouco. Não gosto deles não, nem um pouco, é só. (ALUNA DA ESCOLA MUNICIPAL LUIZ ANTÔNIO ÁLVARES GONÇALVES)

Para além da negação de contato com os povos indígenas, identificamos nas falas acima, mais uma vez, a necessidade de demarcar mundos distintos que separam o "eu" do "outro".

A palavra diferente aparece sempre associada à ideia de superioridade/inferioridade, de oposições binárias, de um sistema classificatório: de um lado "nós", do outro lado "eles".

Essa visão não permeou todas as atividades produzidas, uma vez que em alguns trabalhos identificamos algumas contradições no pensamento dos alunos, como podemos verificar no texto seguir:

Os povos indígenas de Dourados são vagabundos, eles bebem se drogam e ocupam fazendas, recebem terras, alimentos e dinheiro do governo. E ainda reclamam... A vida de um indígena, eu acho que é ficar deitado na rede, bebendo e se drogando. Os povos indígenas além de tudo roubam, saem por aí pedindo as coisas na cidade. Os terrenos que ganham da prefeitura eles vendem ou deixam largado como terreno baldio. Eu não me relaciono com os povos indígenas, mas tudo que eu escrevi aqui já li por aí.

Coisas que eu também penso: os índios são discriminados na sociedade porque se vestem mal e moram na aldeia. Mas o índio também é brasileiro, ser humano. Eles foram os primeiros povos a habitar o Brasil. Nós temos que agradecer por eles terem dividido este país com todos. 


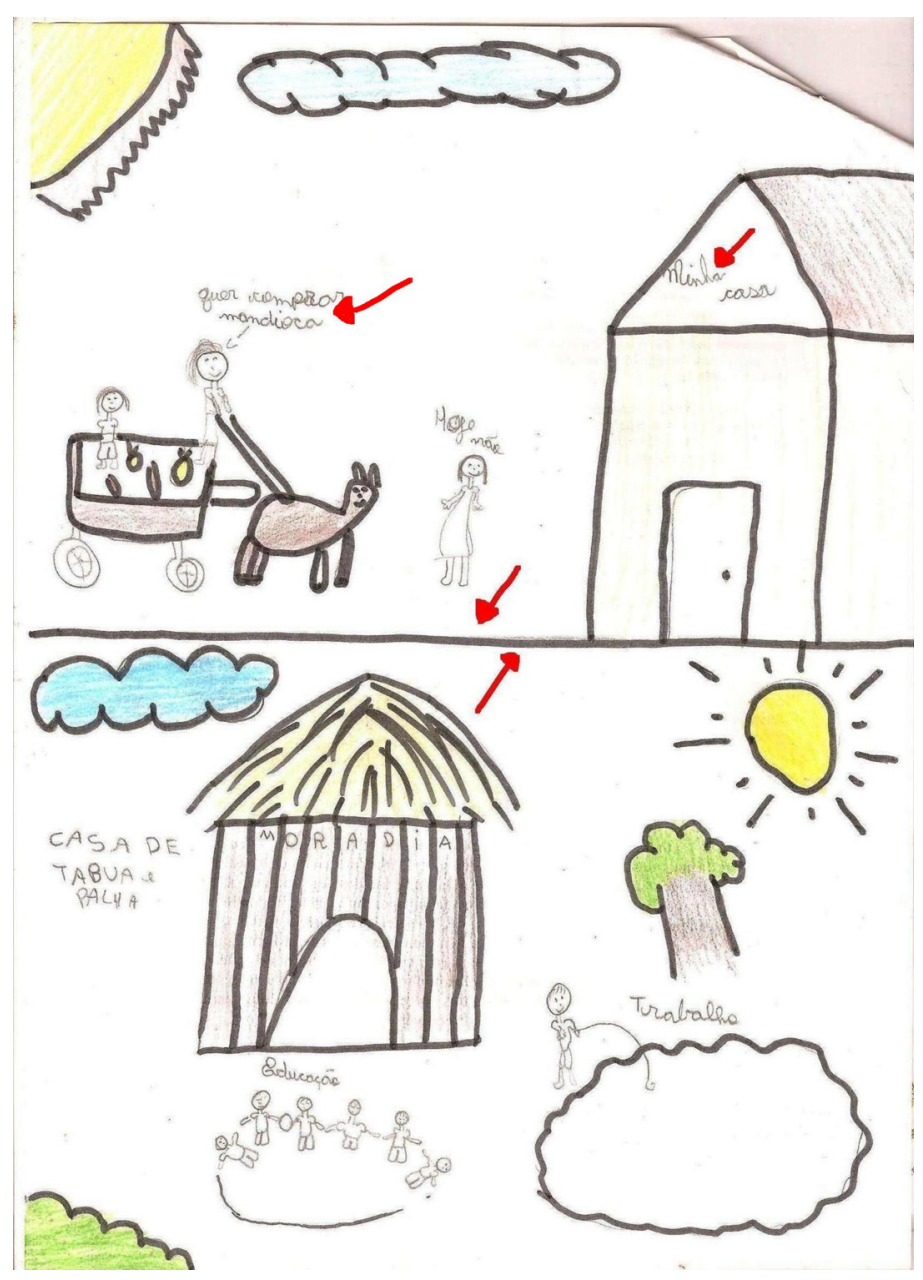

Figura 3 - Representação de aluno do Ensino Fundamental sobre sua relação com os povos indígenas de Dourados (MS)

Fonte: Arquivo pessoal das autoras

É interessante observar que, num primeiro momento do texto, o aluno apresenta uma série de elementos que caracterizam os indígenas como bêbados e vagabundos afirmando que sabe disso porque "já leu por aí", ou seja, apesar de não se relacionar com os indígenas, sua concepção sobre eles é formada a partir dos meios de comunicação (é provável que o aluno se refira à mídia impressa).

No entanto, num segundo momento, o mesmo aluno afirma que "os índios são discriminados porque se vestem mal e moram na aldeia" e que "nós temos que agradecer por eles terem dividido este país com todos", o que mostra que o aluno identifica elementos que contribuem para os processos discriminatórios construídos em relação aos indígenas.

Mesmo em textos e desenhos em que inicialmente identificamos um olhar mais crítico sobre o tema proposto, os conflitos acabam por aparecer, ora em uma linha que divide "meu mundo" do "mundo outro", ora em falas que acabam por contradizer a ideia inicialmente colocada:

Os povos indígenas foram os primeiros a habitar o nosso Estado. Mas nós seres humanos acabamos tomando tudo deles. Mas os "índios" também se acomodaram com essa situação. Isso é culpa da prefeitura que vivi dando cestas básicas para eles. (ALUNO DA ESCOLA MUNICIPAL LUIZ ANTÔNIO ÁLVARES GONÇALVES) 


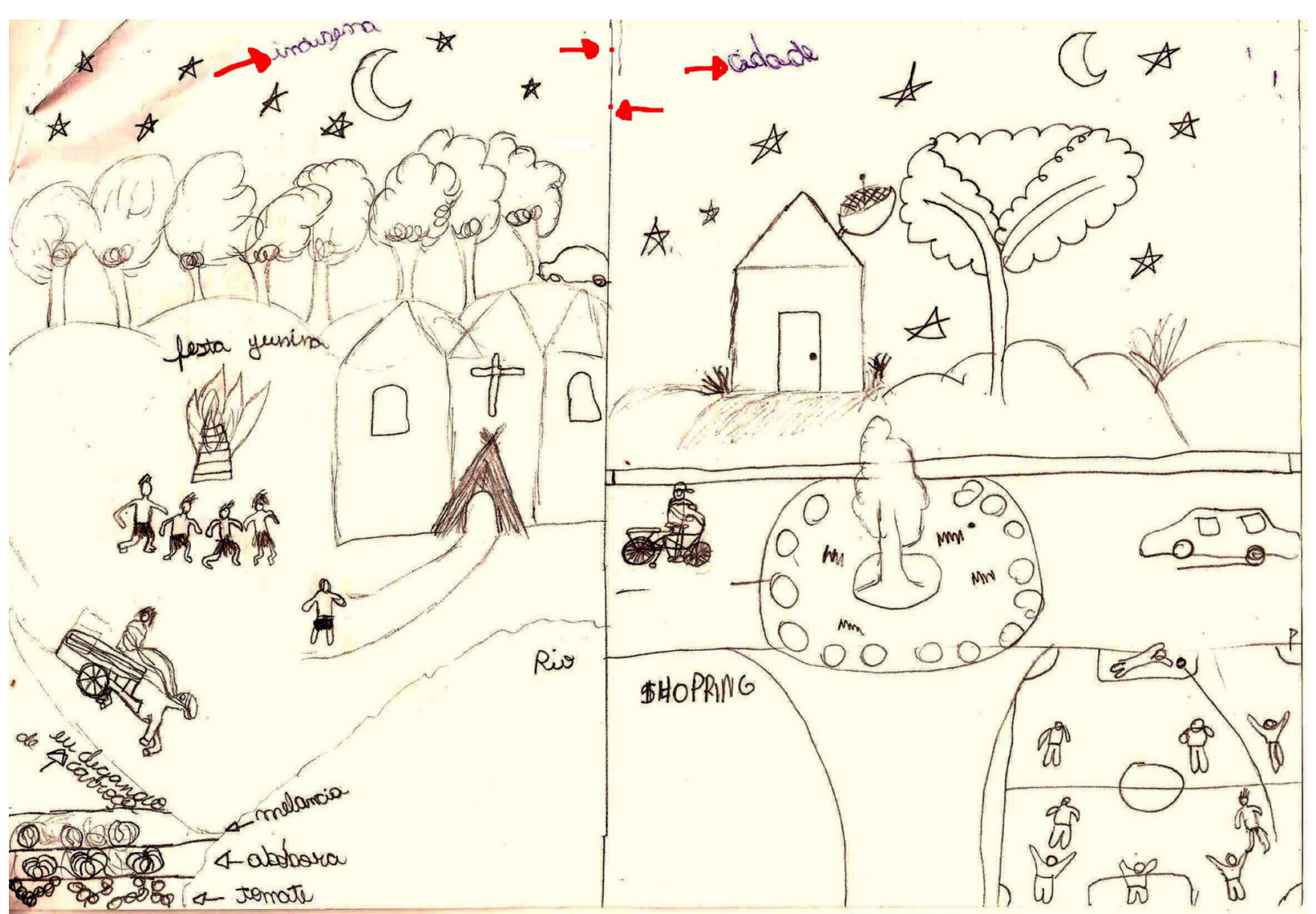

Figura 4 - Representação de aluno do Ensino Fundamental sobre sua relação com os povos indígenas de Dourados (MS)

Fonte: Arquivo pessoal das autoras

Nesse texto, mais uma vez, fica evidente a ideia de que os indígenas são preguiçosos ou vagabundos na medida em que "se acomodaram com essa situação", conforme expressa o aluno.

A partir das concepções até aqui expostas e analisadas, podemos perceber a necessidade de questionarmos e refletirmos sobre a identidade e a diferença como relações de poder.

A construção do indígena como o "outro" hierarquicamente inferior a "nós" expressa nas concepções dos alunos mostra que a afirmação da identidade e a enunciação da diferença traduzem o desejo de diferentes grupos sociais, assimetricamente situados, de garantir o acesso privilegiado aos bens sociais. Verificamos, neste caso, a marcação da diferença tanto por meio de sistemas simbólicos de representação, quanto por meio de formas de exclusão social.

\section{CONSIDERAÇÕES FINAIS}

Neste texto procuramos mostrar a importância da discussão sobre identidade analisando as concepções expressas por alunos do Ensino Fundamental sobre os povos indígenas de Dourados (MS), município no qual esses alunos moram e estudam e que se configura, em nosso entendimento, numa situação de fronteira.

A fronteira, neste caso, foi entendida como lugar da alteridade, um território de invenção do outro, onde o indivíduo procura se reconhecer frente à alteridade e não apenas enquanto limite político-administrativo, embora o município em foco esteja localizado na faixa de fronteira internacional.

Entendemos que as especificidades que caracterizam o município de Dourados (MS), sobretudo a presença significativa de populações indígenas em contato cotidiano com os moradores não indígenas, estabelece uma situação constante de fronteira na qual as relações entre o "eu" e 
o "outro" são pautadas pela marcação das diferenças. Tais diferenças, em grande medida, podem ser analisadas no contexto exposto por Martins (1997) para o qual "o desencontro na fronteira é o desencontro de temporalidades históricas, pois cada um desses grupos está situado diversamente no tempo da História."

Desta forma, de um lado, tem-se o não indígena, considerado "civilizado", "avançado", aquele que "evoluiu" na perspectiva do progresso do mundo moderno capitalista, e de outro, o indígena, "atrasado", que a partir dessa mesma perspectiva pertenceria ao passado. Esta distinção entre o "eu" e o "outro" pautada numa dada concepção de evolução ou cronologia temporal demarca as principais diferenças entre os grupos ali presentes.

Conforme pudemos verificar, as concepções expressas nos desenhos e textos elaborados pelos alunos remetem justamente a esse entendimento em relação às diferenças entre "eles" e os "outros". A análise do material produzido pelos alunos demonstra uma visão dos povos indígenas como sendo homogêneos, de uma identidade única e fixa, na qual prevalece o estereótipo do índio atrasado, preguiçoso, bêbado, drogado e violento.

As diferenças, assim estabelecidas, constroem identidades sob a forma de oposições binárias, conforme exposto por Woodward (2009). Ficou evidente que a identidade dos alunos, em sua maioria não índios, define-se em relação à diferença com os índios, configurando-se enquanto um processo de produção social permeado por relações de poder. A hierarquia estabelecida a partir das diferenças confere aos indígenas uma posição inferior na sociedade e que se materializa nas mais diversas formas de exclusão social, conforme relatado pelos próprios alunos indígenas.

Por outro lado, é importante destacar que apesar da diferença ser construída negativamente, por meio da exclusão ou da marginalização daquelas pessoas identificadas como os "outros", como o caso dos indígenas em Dourados (MS), ela também pode ser celebrada como fonte da diversidade, heterogeneidade e hibridismo.

\section{REFERÊNCIA BIBLIOGRÁFICA}

BARROS, Diana Luz Pessoa de. O discurso intolerante: primeiros estudos. Disponível em: http://www. rumoatolerancia.fflch.usp.br/node/2186. Acesso em 29 jun. 2011.

BAUMAN, Zygmund. Identidade. Rio de Janeiro: Jorge Zahar Editor, 2005.

BENTO, André. MS tem a 2a maior população indígena do País; em Dourados vivem mais de 13 mil. GD NEWS. Dourados, 05/02/2011. Disponível em http://www.gdnews.com.br/noticia/geral/10,2607,ms-tem-a-2-maior-populacao-indigena-do-pais-em-dourados-vivem-mais-de-13-mil. Acessado em 12/01/2012.

BHABA, Hommi. O local da cultura. Belo Horizonte: Ed. da UFMG, 2008.

DILLMANN, Geovana. MS é o segundo estado com maior população indígena do país. JORNAL ALTO TAQUARI. Mato Grosso do Sul, 29/04/2011. Disponível em: http:/www.idest.com.br/noticia.asp?id=25547. Acessado em: 12/01/2012.

GUERRA, Idalina. Modos de Vida: novos percursos e novos conceitos. Sociologia: problemas e Práticas. Lisboa: CIES, ISCTE-IUL, CELTA, n 13, março, p. 59-74, 1993.

HAESBAERT, Rogério. Identidades Territoriais. In: ROSENDAHL, Zeny; CORRÊA, Roberto Lobato. Manifestações da cultura no espaço. Rio de Janeiro, RJ: EdUERJ, 1999. p. 169-189

HAESBAERT, Rogério. O Mito da Desterritorialização. Rio de Janeiro, RJ: Bertrand Brasil, 2004.

HALL, Stuart. Quem precisa da identidade. In: SILVA, Tomaz Tadeu da. Identidade e Diferença: A perspectiva dos Estudos Culturais. Petrópolis, RJ: Vozes, 2000, p. 103-133.

HALL, Stuart. Identidade cultural na pós-modernidade. Rio de Janeiro: DP\&A, 2006.

HANCIAU, Núbia J. Entre-lugar. In: FIGUEIREDO, Eurídice (Org.) Conceitos de Literatura e cultura. Juiz de Fora: UFJF, 2005, p. 125-142.

MARTINS, José de S. Fronteira: a degradação do Outro nos confins do humano. São Paulo: Hucitec, 1997. $213 \mathrm{p}$. 
PESAVENTO, Sandra. (Org.) Fronteiras do milênio. Porto Alegre: Ed. da Universidade, 2001.

SILVA, Tomaz T. da. A produção social da identidade e da diferença. In: SILVA, Tomaz T. da (Org.) Identidade e diferença: a perspectiva dos Estudos Culturais. Petrópolis: Vozes, 2006, p. 73-102.

TUBINO, Fidel. Entre el multiculturalismo y la interculturalidad: más allá de la discriminación positiva. In: Fuller, Norma (Ed.) Interculturalidad y política. Desafíos y posibilidades. Lima: Red para el Desarrollo de las Ciencias Sociales en el Perú, 2002, p. 51-76.

TUBINO, Fidel. Del interculturalismo funcional al interculturalismo crítico. In: Mario SAMANIEGO, Mario; GARBARINI, Carmen (Comps.). Rostros y fronteras de la identidad. Temuco: Universidad Católica de Temuco, 2004, p. 151-164.

WOODWARD, Kathryn. Identidade e diferença: uma introdução teórica e conceitual. In: SILVA, Tomaz T. da (Org.) Identidade e diferença: a perspectiva dos Estudos Culturais. Petrópolis: Vozes, 2006, p. 07-72.

Trabalho enviado em fevereiro de 2014

Trabalho aceito em março de 2014 